\title{
A Brief Introduction of the Special Section : Social Media and Social Participation
}

\section{Jianbin Jin, Special Section Editor School of Journalism and Communication, Tsinghua University, China}

One of the most significant phenomena characterized the present era is the surge of social media, as well as their interwoven association with the ongoing social changes across the globe. It was based on such observation and belief that when I was commissioned by the Journal Editorial Board to organize a special session, social media and social participation popped out as a natural choice for the possible theme of the session.

The special session is composed of three research articles. Wenny Cao, Angus Cheong and Zizi Li present their investigation of social media's role in a social movement took place in Macao early this year, i.e., the protest against the Retirement Package Bill. Combining large-scale data mining approach with manual coding of traditional content analysis, they managed to map out how Facebook had functioned as one of the principal platforms in mobilizing and organizing this impressive collective action which eventually led to the withdrawal of the bill. The second paper is coauthored by Professor Fei Shen and Professor Hongzhong Zhang. Considering the rise of social media in the general landscape of information and communication system, they raise a concern about the influence of widespread use of social media on the perceived media credibility. The findings of their study are very interesting: Weibo use was not related to one's credibility perception toward traditional media, while did show different impacts on people's evaluation of Weibo's credibility per se. The third study reported in this session is from Professor Leah Xiufang Li who examined how social media functioned in disaster management with a comparative perspective across these years. According to her study, amid natural disastrous situations, social media's role in information dissemination and resource mobilization has dramatically heightened over the years. 
All of the three studies are based on the context of China, a country and economy undergoing drastic social change and transition. However, the concerns these authors raised, i.e., the social media and social participation, are apparently significant beyond that geographic boundary, and might serve to inspire a couple of further investigations under the similar framework of new media and society. We are sure this should continue to be a promising and rewarding research field with crucial social significance and theoretical potentiality.

I would like to take the chance to thank all the authors for their very positive responses to my invitation of submission preparation for the themed session. Much gratitude should go to all of our reviewers who devoted their time and professional opinions which have been an indispensable part in the process of quality content production. Huge special thanks go to Sarah LoCascio who has been acting as the journal coordinator. I am very much sure that without her persistent effort in pushing me and all of the authors of the session to finish our work as promised, the release of this special session will be definitely impossible.

\section{Biographical Note}

Jianbin Jin is currently an Associate Professor of the School of Journalism and Communication, Tsinghua University, China. He has interests in the adoption, use and social effects of new media, communication theory and research methods. He has published two books and a couple of research papers in the area of Internet studies.

He can be reached at: jinjb@mail.tsinghua.edu.cn 